\title{
TINJAUAN FAKTOR-FAKTOR PENGHAMBAT PELAKSANAAN TRACER DI RUMAH SAKIT GRIYA HUSADA MADIUN
}

\author{
Musfika \\ Program Studi Rekam Medis dan Informasi Kesehatan, Sekolah Tinggi Ilmu \\ Kesehatan Buana Husada Ponorogo \\ Email : musfika.oct993@gmail.com
}

\begin{abstract}
The implementation of medical record document storage system is still decentralized, the storage (filling) in retrieving medical record documents does not use tracers or outgoing document markers, so that on the shelf there is no marker that where the position of medical record documents coming out of the storage rack (filling). The purpose of this study was to determine what factors were hampering the use of medical record tracers. This research design uses descriptive research design. Data collection methods and data collection used in this study by observation and interview. The variables in this study are independent variables that inhibit the implementation of the Tracer. The population and sample in this study were medical record officers at Griya Husada Madiun Hospital. Based on the results of the study at first the Griya Husada Hospital had used a tracer but until now the use of the tracer stopped because it was caused by several factors that hindered the implementation of the tracer in terms of man, method, material, money and machine namely there were no special officers in the filling section, Griya Hospital Husada, there is no tracer printing machine. This will have an impact on misplacement, misfile, and make it difficult to return the medical record file in order.
\end{abstract}

Keywords: Tracer, misfile

\section{PENDAHULUAN}

Penyelenggara kesehatan harus dapat mendokumentasikan data serta setiap tindakan dan pelayanan yang telah diberikan kepada pasien kedalam dokumen yang di sebut dengan Rekam Medis. Rekam medis yang akurat dan dapat dipercaya adalah rekam medis yang sudah diolah menjadi sebuah informasi dan terjamin mutunya dengan baik. Pelayanan yang berkualitas dan bermutu di pengaruhi oleh beberapa faktor salah satunya adalah penyelenggaraan rekam medis yang baik. Salah satu kegiatan yang dilakukan dalam pengolahan rekam medis adalah sistem penyimpanan (filling).

Berdasarkan studi pendahuluan yang dilakukan peneliti pada tanggal 26 Desember 2018, Rumah sakit Griya
Husada Madiun sistem penyimpanannya masih desentralisasi yaitu Rumah Sakit Griya Husada Madiun, penyimpanan berkas rekam medis disimpan secara terpisah berkas rekam medis rawat inap di simpan di ruang filling rawat inap, berkas rekam medis IGD di simpan ruang filling IGD sedangkan untuk berkas rekam medis rawat jalan itu DRM di simpan di poli, dalam pengambilan berkas rekam medis tidak menggunakan tracer sebagai petunjuk keluar berkas rekam medis. Karena belum adanya petugas khusus dibagain filling, ada SOP tentang penggunaan tracer atau petunjuk keluar berkas rekam medis akan tetapi tidak digunakan. Rekam medis yang keluar dari rak penyimpanan tanpa menggunakan tracer atau petunjuk keluar dari rak penyimpanan sehingga ketika petugas 
ingin mengembalikan berkas rekam medis ke rak penyimpanan akan membutuhkan waktu yang cukup lama dan bisa juga terjadi missfile atau adanya dokumen rekam medis yang salah tempat. Tingkat kejadian misfile di Rumah Sakit Griya Husada Masih $0,3 \%$ akan tetapi dengan adanya tracer sebagai pengganti berkas rekam medis yang keluar dari rak penyimpanan bisa meminimalisir terjadinya missfile.

Tracer dapat dibuat dengan bahan potongan kertas A4, dan harus tercantum nama pasien, nomor rekam medis, tanggal keluar, poli tujuan atau nama peminjam, keterangan dan dibuat dengan warna yang kontraks dengan warna map berkas rekam medis agar mempermudah petugas melihat letak dimana saja berkas rekam medis yang keluar dari rak penyimpanan. Sebelumnya Rumah Sakit Griya Husada sudah menggunakan tracer akan tetapi penggunaannya hanya sampai dengan 5-6 tahun yang lalu. penyimpanan berkas rekam medis disimpan secara terpisah berkas rekam medis rawat inap di simpan di ruang filling rawat inap, berkas rekam medis IGD di simpan ruang filling IGD sedangkan untuk berkas rekam medis rawat jalan itu masing-masing DRM di simpan di poli, sehingga petugas tidak menggunakan tracer, beberapa faktor lainnya antara lain petugas rekam medis yang kurang, tidak adanya petugas khusus bagian filling, dan ada SOP tentang penggunaan tracer namun tidak digunakan. Tujuan dari penelitian ini yaitu mengetahui faktorfaktor penghambat pelaksanaan tracer berdasarkan man, method, material, money dan machine.

\section{METODE PENELITIAN}

Jenis penelitian yang digunakan pada penelitian ini yaitu penelitian deskriptif kualitatif. Lokasi penelitian yaitu di Rumah Sakit Griya Husada Madiun. Sampel penelitian ini yaitu petugas rekam medis yang berjumlah 3 orang. Variabel dalam penelitian ini adalah variabel independen. Dalam penelitian ini peneliti mengambil teknik pengumpulan data dengan cara wawancara dan observasi.

\section{HASIL PENELITIAN}

Berdasarkan hasil wawancara yang dilakukan peneliti pada tanggal 04 Mei 2019 kepada petugas rekam medis terkait penghambat pelaksanaan penggunaan tracer bahwa Rumah Sakit Griya husada sistem penyimpanannya masih desentralisasi dimana untuk penyimpanan dokumen rekam medisnya di pisah, karena kurangnya ruang filling sebab ruang filling jadi satu dengan pengolahan rekam medis seperti assembeling, coding / indexing. untuk mengetahui faktor apa saja yang menghambat pelaksanaan penggunaan tracer berdasarkan man, method, material, money dan machine diuraikan sebagai berikut :

1. Man ( sumber daya manusia)

Rumah Sakit Griya Husada sumber daya manusianya untuk bagian rekam medis berjumlah 5 orang yang sistem kerjanya dibagi menjadi dua shift, akan tetapi belum adanya petugas khusus di bagian filling atau tempat penyimpanan dokumen rekam medis pasien, berdasarkan hasil wawancara yang dilakukan peneliti kepada petugas yang ada disana memang untuk petugas khusus dibagian filling belum ada, jadi yang menyiapkan dokumen rekam medis pasien yang datang berobat ke rumah sakit hanya petugas yang ada pada saat itu dan untuk pengembalian dokumen rekam medis pasien setelah berobat dari poliklinik ataupun rawat inap, petugas poli mengembalikan dokumen rekam medis pasien ke bagian rekam 
medis untuk dilakukan pengimputan data pasien setelah berobat, setelah data pasien tersebut di input maka petugas rekam medis yang ada pada saat itu mengembalikan ke rak penyimpanan dokumen rekam medis setelah pasien selesai berobat.

2. Method ( metode / cara )

Rumah Sakit Griya Husada acuan atau pedoman yang digunakan dalam melakukan pekerjaan yaitu standar operasional prosedur, berdasarkan hasil wawancara yang dilakukan peneliti kepada petugas rekam medis di rumah sakit griya husada medis sebenarnya untuk standar operasional prosedur penggunaan tracer rekam medis sudah ada dan pernah digunakan tetapi tidak berjalan karena petugas yang khusus dibagian filling belum ada. Sehingga tracer tidak digunakan.

3. Material (Bahan Baku)

Rumah Sakit Griya Husada dalam pengambilan dokumen rekam medis di rak penyimpanan pernah menggunakan tracer sebagai penanda adanya dokumen rekam medis yang keluar dari rak penyimpanan. Untuk penggunaan tracer bahan baku yang digunakan yaitu kertas, yang diselipkan diantara dokumen rekam medis sebagai pengganti dokumen rekam medis yang keluar dari rak penyimpanan. Sedangkan icon yang ada didalamnya yaitu nomor rekam medis pasien, nama pasien, nama peminjam, dan keterangan untuk apa berkas rekam medis itu dipinjam. Berdasarkan hasil wawancara kepada petugas rekam medis yang ada di rumah sakit untuk bahan baku pembuatan tracer yaitu kertas hvs yang di print.

\section{Money (Anggaran)}

Rumah Sakit Griya Husada untuk terkait anggaran dalam pembuatan tracer ini belum ada, berdasarkan hasil wawancara yang dilakukan peneliti kepada petugas rekam medis yang ada di rumah sakit griya husada untuk anggaran khusus dibagian filling memang belum ada karena untuk pembuatan tracer ini tidak memerlukan biaya yang begitu banyak. Penerapan tracer juga dapat meminimalisir terjadinya misfile atau adanya dokumen rekam medis yang salah tempat, karena apabila ada dokumen rekam medis yang salah tempat atau hilang otomatis pengambilan dokumen rekam medis pasien agak lama dan pasien dibuatkan dokumen rekam medis baru lagi. Untuk itu penerapan tracer sebagai pelacak dokumen rekam medis yang keluar dari rak penyimpanan sangat perlu.

\section{Machine (Alat)}

Rumah Sakit Griya Husada untuk alat yang digunakan dalam pembuatan tracer yaitu mesin pencetak atau print, dan untuk penyimpanan dokumen rekam medis pasien yaitu rak penyimpanan, berdasarkan hasil wawancara dengan petugas rekam medis untuk alat pencetak tracer yaitu print sedangkan untuk rak penyimpanannya itu sudah ada dengan kondisi masih baik, jadi yang hanya perlu ditambahkan yaitu mesin pencetak tracer agar tracer kembali dijalankan seperti dulu lagi.

\section{PEMBAHASAN}

Berdasarkan hasil observasi yang dilakukan peneliti pada tanggal $04 \mathrm{Mei}$ 2019 Sistem penyimpanan di Rumah Sakit Griya Husada yaitu menggunakan sistem penyimpanan desetralisasi, yang mana tempat 
penyimpanan dokumen rekam medis rawat jalan dan rawat inapnya itu dipisah. Sistem pengambilan dokumen rekam medis pasien di rak rak penyimpanan yaitu dengan cara dokumen rekam medis pasien yang datang berobat langsung diambilkan di rak penyimpanan kemudian petugas menulisnya di buku ekspedisi akan tetapi pengganti dokumen rekam medis yang keluar dari rak peniyimpanan itu tidak ada.

Menurut Savitri (2011), beberapa fasilitas di ruang penyimpanan berkas rekam medis diantaranya ada :

a. Ruang dengan suhu ideal untuk penyimpanan berkas rekam medis pasien dan keamanan dari serangan fisik lainnya.

b. Alat penyimpanan berkas rekam medis, bisa menggunakan Roll o pack, Rak terbuka dan Filling cabinet.

c. Tracer yang digunakan sebagai pengganti berkas rekam medis pasien di rak penyimpanan yang dapat digunakan untuk menelusur keberadaan berkas rekam medis.

Sistem pengambilan dokumen rekam medis pasien di Rumah Sakit Griya Husada yaitu petugas langsung mengambil dokumen rekam medisnya di rak penyimpanan dokumen rekam medis tanpa menyelipkan tracer atau membuat tanda dimana letak dokumen rekam medis yang keluar dari rak penyimpanan sehingga ketika ingin mengembalikan di rak penyimpanan petugas dapat melihat dimana saja letak dokumen rekam medis yang keluar dari rak penyimpanan.

Berdasarkan hasil wawancara yang dilakukan peneliti guna mengetahui faktor apa saja yang mempengaruhi pelaksanaan penggunaan tracer dengan melihat dari segi man, method, material, money, dan machine yaitu diuraikan sebagai berikut :
1. Man (sumber daya manusia)

Pelaksanaan penyimpanan dan pengembalian dokumen rekam medis di rak penyimpanan menggunakan tracer sudah dilakukan sejak dulu akan tetapi sampai saat ini pelaksanaan penggunaan tracer berhenti, karena dulu petugas rekam medis hanya berjumlah 2 orang, dan sekarang petugas berjumlah 5 orang dengan pembagian 2 shift diantaranya 3 shift pagi dan 2 orang shift sore, tapi hingga saat ini penggunaan tracer belum juga di jalankan karena belum adanya pembagian tugas, belum telatennya petugas dalam penggunaan tracer.

Penelitian Savitri (2015), ini ditemukan masalah di tempat penyimpanan dokumen rekam medis yaitu tracer tidak digunakan sebagai kartu pelacak dokumen rekam medis keluar dari rak penyimpanan dikarenakan jumlah petugas terbatas, adanya anggapan bahwa penggunaan tracer akan menambah lama proses penyimpanan berkas rekam medis

Pelaksanaan penyimpanan dan pengembalian dokumen rekam medis perlu adanya petugas khusus di bagian filling agar petugas tersebut berfokus kepada satu tujuan dan perlu ketelatenan petugas dalam penggunaan tracer agar penggunaan tracer dapat dijalankan kembali seperti dulu, diikutkan pelatihan rekam medis terkait penyimpanan dan pengembalian dokumen rekam medis.

2. Methode (metode)

Metode pengambilan dokumen rekam medis di rak penyimpanan yaitu tanpa menggunakan kartu tanda (tracer) adanya dokumen rekam medis yang keluar dari rak penyimpanan, pedoman yang digunakan dalam pelaksanaan 
penggunaan tracer yaitu standar operasional prosedur.

Penelitian Ine Pratiwi (2017), ini ditemukan masalah tracer di RS Panti Nugroho belum digunakan dengan baik karena menurut petugas, tracer tersebut menggunakan kertas sehingga tidak praktis atau ribet, mudah rusak dan robek, maka dari itu petugas enggan menggunakan tracer. Sehingga ada rekam medis sering terselip atau salah letak (misfile).

Terdapat prosedur tentang penyimpanan dan pengembalian dokumen rekam medis yang tidak dijalankan oleh petugas dalam hal penggunaan tracer, dan petugas penyimpanan berkas rekam medis perlu diberikan sosialisasi penggunaan tracer dalam hal pengambilan dan penyimpanan berkas rekam medis. Sosialisasi pelaksanaan tracer dapat dilaksanakan pada waktu rapat yang dipimpin oleh kepala instalasi rekam medis dan ditujukan kepada semua petugas rekam medis.

3. Material (bahan baku)

Rumah Sakit Griya Husada Madiun untuk bahan baku yang digunakan dalam pembuatan tracer ini yaitu kertas dengan ukuran yang lebih kecil dari pada dokumen rekam medis pasien yang diselipkan apabila ada dokumen rekam medis pasien yang keluar dari rak penyimpanan. Berdasarkan hasil wawancara kepada petugas rekam medis untuk bahan baku tracer hanya ketas hvs dan tracer juga tidak di cetak terlalu banyak hanya saja untuk persediaan.

Kertas yang digunakan untuk pembuatan tracer yaitu kertas hvs dan apabila sewaktu-waktu kertasnya habis, bisa mencetak diluar rumah sakit karena pembuatan tracer ini tidak memerlukan banyak biaya.
Penerapan penggunaan tracer juga dapat meminimalisir terjadinya misfile atau adanya dokumen rekam medis salah tempat yang disimpan di rak penyimpanan.

4. Money (anggaran)

Rumah Sakit Griya Husada untuk anggaran di bagian filling memang belum ada Berdasarkan hasil wawancara dengan petugas rekam medis terkait anggaran pembuatan tracer ini memang belum ada karena hal ini tidak terlalu membutuhkan biaya yang banyak karena pembuatan tracer sendiri dapat di cetak sendiri. Adanya anggaran khusus dibagian filling agar apabila sewaktu-waktu ada salah satu kebutuhan yang kurang atau belum terpenuhi itu anggarannya dapat digunakan sebagai kelancaran suatu pekerjaan yang dijalankan petugas.

5. Machine (mesin / alat)

Rumah Sakit Griya Husada sistem penyimpanan dokumen rekam medis pasien yaitu sistem penyimpanan desentralisasi dan menggunakan rak penyimpanan terbuka. Berdasarkan hasil wawancara yang dilakukan peneliti kepada petugas rekam medis yaitu untuk peralatan yang digunakan yaitu hanya print dan rak rekam medis, Kegunaan tracer juga dapat meminimalisir terjadinya misfile atau dokumen rekam medis yang hilang atau salah tempat pada rak penyimpanan.

Peralatan yang ada yaitu rak penyimpanan dokumen rekam medis dan print yang digunakan untuk mencetak tracer. untuk rak penyimpanan sudah tersedia dalam kondisi baik, untuk pencetak tracer sendiri hanya menggunakan print, apabila memang belum ada alat pencetak tracer dapat di cetak di luar rumah sakit. 
Dari kelima faktor penghambat semuanya saling berkaitan, namun faktor yang paling mempengaruihi yaitu dari faktor sumber daya manusia, jika dari kebutuhan peralatan, bahan baku terpenuhi tapi tanpa adanya sumber daya yang berkompetensi, maka penyelenggaraan penggunaan tracer tidak akan berjalan dengan lancar hal ini perlu dukungan dari kebijakan rumah sakit terkait penyimpanan dokumen rekam medis.

\section{KESIMPULAN}

1. Faktor penghambat pelaksanaan tracer dari segi man

Pelaksanaan penyimpanan dan pengembalian dokumen rekam medis di rak penyimpanan menggunakan tracer sudah dilakukan sejak dulu akan tetapi sampai saat ini pelaksanaan penggunaan tracer berhenti, karena dulu petugas rekam medis hanya berjumlah 2 orang, dan sekarang petugas berjumlah 5 orang dengan pembagian 2 shift diantaranya 3 shift pagi dan 2 orang shift sore, tapi hingga saat ini penggunaan tracer belum juga di jalankan karena belum adanya pembagian tugas, belum telatennya petugas dalam penggunaan tracer.

2. Faktor penghambat pelaksanaan tracer dari segi method

Metode pengambilan dokumen rekam medis di rak penyimpanan yaitu tanpa menggunakan kartu tanda (tracer) adanya dokumen rekam medis yang keluar dari rak penyimpanan, pedoman yang digunakan dalam pelaksanaan penggunaan tracer yaitu standar operasional prosedur.

3. Faktor penghambat pelaksanaan tracer dari segi material

Bahan baku yang digunakan dalam pembuatan tracer ini yaitu kertas dengan ukuran yang lebih kecil dari pada dokumen rekam medis pasien yang diselipkan apabila ada dokumen rekam medis pasien yang keluar dari rak penyimpanan. Berdasarkan hasil wawancara kepada petugas rekam medis untuk bahan baku tracer hanya ketas hvs dan tracer juga tidak di cetak terlalu banyak hanya saja untuk persediaan.

4. Faktor penghambat pelaksanaan tracer dari segi money

Anggaran pembuatan tracer ini memang belum ada karena hal ini tidak terlalu membutuhkan biaya yang banyak karena pembuatan tracer sendiri dapat di cetak sendiri.

5. Faktor penghambat pelaksanaan tracer dari segi machine

Peralatan yang digunakan yaitu hanya print dan rak rekam medis, Kegunaan tracer juga dapat meminimalisir terjadinya misfile atau dokumen rekam medis yang hilang atau salah tempat pada rak penyimpanan.

\section{SARAN}

Dari hasil penelitian mengenai faktor-faktor penghambat pelaksanaan tracer, peneliti berharap penelitian ini dapat berguna bagi :

1. Rumah Sakit Griya Husada Madiun Dapat mengevaluasi pengelolahan rekam medis dan dapat pertimbangan untuk menyusun sebuah kebijakan dalam meningkatkan mutu pelayanan rekam medis.

2. Institusi Pendidikan

Hasil penelitian ini diharapkan dapat menjadi tambahan wawasan di institusi pendidikan khususnya di bagian rekam medis.

3. Bagi Peneliti

Dengan penelitian yang telah dilakukan diharapkan dapat menambah wawasan dan pengetahuan. 
4. Bagi Peneliti Lain

Sebagai bahan referensi untuk penelitian selanjutnya.

\section{DAFTAR PUSTAKA}

Savitri (2011), Pentingnya Tracer Sebagai Kartu Pelacak Berkas Rekam Medis Keluar Dari Rak Penyimpanan di Puskesmas Dlingo 1 Bantul.

Asmono (2014), Faktor-Faktor Penyebab dan Dampak Tidak Menggunkan Tracer Dibagian Penyimpanan Berkas Rekam Medis Di Rumah Sakit Mata Dr. Yap Yogyakarta.

Ine Pratiwi (2017), Redesain Tracer (Outguide) Pada Penyimpanan Berkas Rekam Medis Di Rumah Sakit Nugroho Sleman Yogyakarta. 